\title{
Estimation of coronary risk factors in British schoolchildren: a preliminary report
}

\author{
N. Armstrong, PhD, FPEA, J. Balding, MMed Sci, P. Gentle, FFCM and B. Kirby, FRCP
}

Schools of Education and Postgraduate Medicine, University of Exeter

\begin{abstract}
Surveys from several countries have identified the presence of risk factors known to be associated with coronary heart disease in children. Data on the distribution of coronary risk factor variables in British children are scarce. This study was therefore designed to test the feasibility of collecting coronary risk factor data from British children and to conduct a preliminary examination of the problem. One hundred and seven children (mean age $12.8 \mathrm{yr}$ ) had their height, weight, triceps skinfold and blood pressure checked. Blood samples for cholesterol and HDL-cholesterol analysis were obtained from 93 children. Peak VO $_{2}$ was determined on 48 children, 76 children had their daily activity monitored and 59 children's stage of sexual maturity was assessed.

The boys' peak $\dot{\mathrm{VO}}_{2}$ was significantly higher than the girls, whether expressed in $1 . \mathrm{min}^{-1}(\mathrm{p}<0.05)$ or ml.kg. ${ }^{-1} \min ^{-1}(p<0.01)$. No other significant differences ( $p>0.05$ ) between the sexes were detected. The results indicate that children have relatively high serum cholesterol levels (boys $4.58 \pm 0.79$; girls $4.72 \pm 0.80$ mmol. $\left.1^{-1}\right)$. The willingness and enthusiasm of the children, parents and schools to take part in the study clearly demonstrated the feasibility of a large scale study being successfully pursued in the United Kingdom.
\end{abstract}

Keywords: Coronary risk factors, children

\section{Introduction}

Saltykov, in his study of the degenerative changes of the aorta, first called attention to the paediatric origin of atherosclerosis when he stated the so-called fatty changes in the arteries of childhood and youth, especially in the aorta, are nothing less than the beginning of atherosclerosis ${ }^{1}$. Many investigators have since described these atherosclerotic lesions and documented their presence in the coronary arteries of children ${ }^{2}$.

A risk factor is an identifiable characteristic which, when present, is associated with a higher than expected incidence of a disease. The concept of coronary risk factors evolved from prospective epidemiological studies relating personal characteristics of participants to subsequent incidence of $\mathrm{CHD}^{3}$.

Address for correspondence: Dr N Armstrong, PEA Research Centre, School of Education, University of Exeter, Exeter EX1 2LU, UK

(C) 1990 Butterworth \& Co (Publishers) Ltd 0306-3674/90/010061-06
The extension of the risk factor concept to children began in the 1960s. More recently, a great deal has been published on the distribution of adult risk factors for coronary artery disease, which include hyperlipidaemia, hypertension, cigarette smoking, physical inactivity and obesity, in several populations of children ${ }^{4}$. The most comprehensive data base to date has been assembled by the Bogalusa Heart Study ${ }^{5}$. The Bogalusa studies have documented the importance of risk factor variable levels to early anatomical changes in both the aorta and the coronary arteries ${ }^{6}$, thereby strongly substantiating the concept that atherosclerosis begins in childhood?

Data on the distribution of coronary risk factor variables in British children are scarce. The relationship of coronary risk factor variables with physical activity and cardiorespiratory fitness remains unexplored in British children. This study was therefore designed to test the feasibility of collecting coronary risk factor data from British children and to conduct a preliminary examination of the problem.

\section{Methods}

It was realised from the onset that there are clear ethical issues concerning the consent of children to participate in research of this nature. Written informed consent was obtained from both parent/ guardian and child before any child was allowed to participate in the project. All aspects of the work were approved in advance by the Exeter Health Authority Ethical Committee. The ethical considerations and the school-based recruitment of subjects have been discussed in more detail elsewhere ${ }^{8}$.

All the children in two mixed ability second year classes, from each of two large community colleges agreed to participate in the research. The sample consisted of a homogenous group of 107 Caucasian children ( 55 boys and 52 girls). Age was computed from date of birth and date of examination. The children from one of the schools ( 29 girls, 30 boys) had their external maturity visually assessed using the indices developed by Tanner ${ }^{9}$.

Height was measured using a Harpenden stadiometer. Weight was measured wearing minimum indoor clothing, without shoes, using scales calibrated against a beam balance (Avery 3306 ABV). Height:weight ratios were compared with those 
recommended by the Royal College of Physicians ${ }^{10}$. Skinfold thickness over the triceps in all subjects and the subscapular region in boys only were measured by an experienced observer using previously calibrated Harpenden calipers.

Blood pressure was measured by two experienced clinicians three times, on the right hand side, with the subject sitting for at least three minutes in a quiet environment. Hawksley Random Zero Sphygmomanometers and appropriate sized cuffs were used for the measurement. The systolic point of appearance of sound (Korotkoff I), the point of muffling (Korotkoff IV) and of disappearance (Korotkoff V) were recorded. Cross-checks were carried out between the observers and the second measurement of the Korotkoff first and fourth points was used in the subsequent analysis. The Korotkoff fourth point was used in preference to the fifth point as it appears to be the best single index of diastolic blood pressure in children $^{11}$.

Nurses familiar to the children sampled blood from an antecubital vein. No more than two attempts to sample blood were allowed on any child, and sufficient blood for analysis was obtained from 49 boys and 44 girls. Samples were coded and rapidly transferred to the area department of biochemistry where the serum was separated within four hours. The serum was analysed for total cholesterol and high density lipoprotein cholesterol (HDL-C) using an IL Multistat III Microcentrifugal Analyser. Total cholesterol was measured using BCL CHOD-PAP Kit and HDL-C was measured using BCL HDL precipitant followed by CHOD-PAP. ${ }^{12,13}$ Both methods are in routine use in the laboratory and the analytical method used between batch precision of determination based on 30 samples from this study had coefficients of variation of 2.4 per cent (total cholesterol) and 2.2 per cent (HDL-C).

No attempt was made to obtain fasting samples. Although fasting samples are not necessary for the determination of cholesterol ${ }^{14}$, they are mandatory for the determination of triglyceride ${ }^{15}$. Serum triglyceride was therefore not determined. Similarly, the determination of low density lipoprotein cholesterol (LDL-C) using the standard Friedewald method ${ }^{16}$ requilies fásting samples, so it was not determined in this study.

The prevalence of cigarette smoking was ascertained from a confidential questionnaire details of which are provided elsewhere ${ }^{8}$.

The peak $\mathrm{VO}_{2}$ of 23 girls and 25 boys was determined during an exercise test which involved running on a motorised treadmill (Woodway), using a continuous, incremental protocol to voluntary exhaustion. The children were first familiarised with the laboratory environment and allowed to practice running on the treadmill. They then warmed up by running on the belt at a speed of $8 \mathrm{~km} \cdot \mathrm{h}^{-1}$ for five minutes. The belt speed was raised to $10 \mathrm{~km} \cdot \mathrm{h}^{-1}$ and the treadmill gradient was elevated by 2.5 per cent at the end of each three minute period. Each child continued running until the test was terminated at the point of voluntary exhaustion i.e. when the child, despite strong verbal encouragement from the experimenters, was unwilling or unable to carry on.
Forty-two per cent of the subjects elicited a $\mathrm{VO}_{2}$ plateau $\left(<2 \mathrm{ml} . \mathrm{kg}^{-1} \mathrm{~min}^{-1}\right)$ but peak $\mathrm{VO}_{2}$ was accepted as a maximal variable in all subjects as in every case peak heart rate levelled off several minutes prior to the final exercise intensity at a value of at least 95 per cent of the age predicted maximum. It is well established that children, if sufficiently encouraged, approach the true limits of maximal oxygen uptake without reaching a plateau in $\mathrm{VO}_{2}{ }^{17}$.

The level of daily physical activity was estimated by monitoring minute-by-minute heart rates continuously over a 12 hour period on a normal schoolday. The Sport Tester 3000 System (Cranlea Medical), described in detail by Karvonen ${ }^{18}$, was used to collect and store data (Figure 1). The Sport Tester 3000 has been found to be a reliable and valid means of recording heart rate with children ${ }^{19}$. A recent survey of the most popular commercially available heart rate monitors concluded that the Sport Tester $\mathbf{3 0 0 0}$ was first choice as "in addition to having excellent validity and stability it permits almost total freedom of motion" ${ }^{\prime 20}$.

A lightweight transmitter and electrodes were fitted to each child's chest and a microcomputer strapped around the wrist in the form of a watch. The monitoring period lasted from about $9.00 \mathrm{~h}$ until $21.00 \mathrm{~h}$. The microcomputers were retrieved the following morning and the data analysed by interfacing with a Polar Electronics micro-computer and printer.

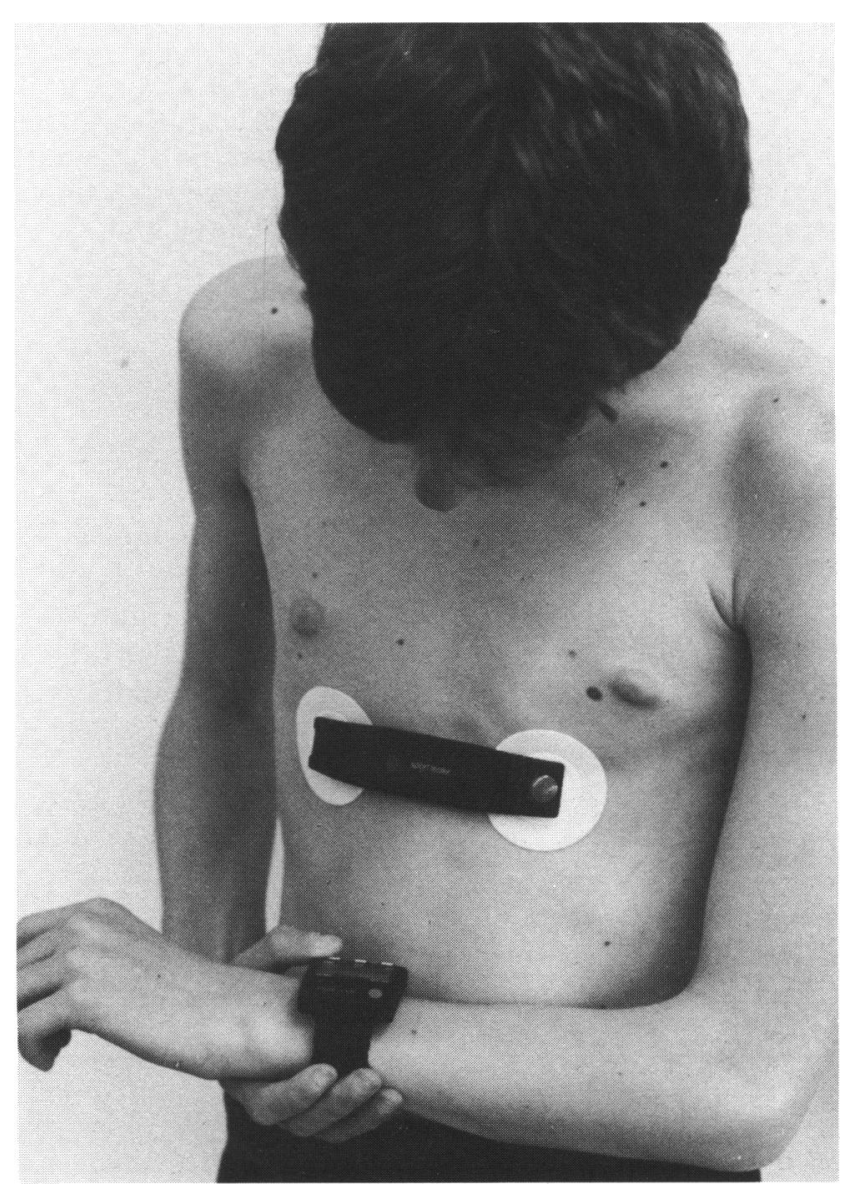

Figure 1. The Sport Tester 3000 System 


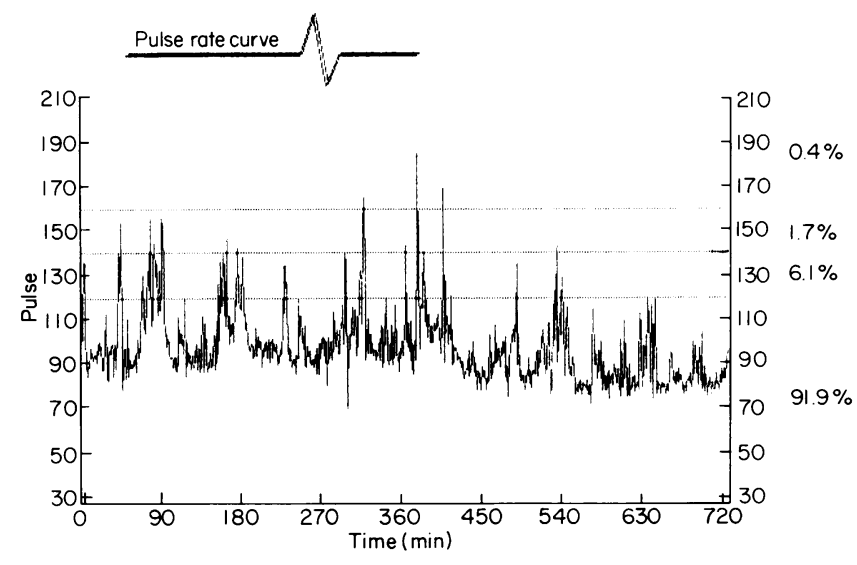

Figure 2. A typical 12 hour heart rate trace

Only full 12 hour records were used in the subsequent analysis and these were obtained from 76 children ( 44 girls and 32 boys). A typical 12 hour trace is illustrated in Figure 2. We were particularly interested in the percentage of time spent with heart rates above 159 beats. min $^{-1}$ as this has been identified as a training threshold for the development of cardiorespiratory fitness in children ${ }^{21}$.

In order to evaluate whether wearing the Sport Tester 3000 restricted the children's physical activity, one of the research group observed 16 physical education lessons in each of which two or three children were wearing Sport Testers. The children were unaware of being observed as they were under the impression that it was the students teaching the lessons who were being scrutinised. No difference between the activity of those wearing the Sport Testers and those not wearing Sport Testers was discernible, and it was concluded that the system did not restrict physical activity.

\section{Results}

Relevant results are displayed in Table 1.

\section{Maturity}

There was no significant difference $(p>0.05)$ in age between the sexes. The analysis of sexual maturity indicated that the girls were more mature than the boys with 60 per cent of the girls and 46 per cent of the boys falling into ratings 3,4 and 5 . Twelve of the girls (48 per cent) self-reported that they had reached menarche. No problems emerged from the assessment of sexual maturity.

\section{Anthropometry}

The girls were significantly taller $(p<0.05)$ than the boys, but there were no significant differences in body weight or triceps skinfold thickness $(p>0.05)$. Using the Royal College of Physicians' ${ }^{10}$ recommendations, ten boys (18.2 per cent) and five girls ( 9.6 per cent) could be classified as being overweight. Discussion with the girls revealed that in future they would raise no objection to having their subscapular skinfold thickness measured by a female investigator.

\section{Blood pressure}

There were no significant differences $(p>0.05)$ between either the diastolic or systolic blood pressures of the girls and boys. Comparisons between studies must be carried out cautiously, but it is interesting to note that the present children compare favourably with other European children measured in Wynder's comprehensive, comparative study of 13 countries $^{22}$. The mean values reported here are close to the 'optimal level of blood pressure' $(110 / 60 \mathrm{mmHg})$ for children of this age as suggested by Wynder. Two of the girls exceeded Wynder's arbitrarily designated diastolic cut-off point for 'high risk' $(85 \mathrm{mmHg})$, but none of the children exceeded his systolic 'high risk' cut-off point of $130 \mathrm{mmHg}$.

\section{Serum cholesterol and HDL-cholesterol}

No significant differences $(p>0.05)$ between girls and boys on either variable were detected. The mean values are similar to those reported from other Northern European countries, but somewhat lower than those originating in Norway $^{22}$. The values of both the boys' and girls' total cholesterol are higher than those previously reported from this country ${ }^{23}$, but this may be explained by the higher HDLcholesterol values in the present study. A feasible, ideal mean level of serum cholesterol of $3.62 \mathrm{mmol}^{-1}$ has been suggested ${ }^{24}$, and this is

Table 1. Physical characteristics, blood pressure, serum cholesterol and peak oxygen uptake by sex

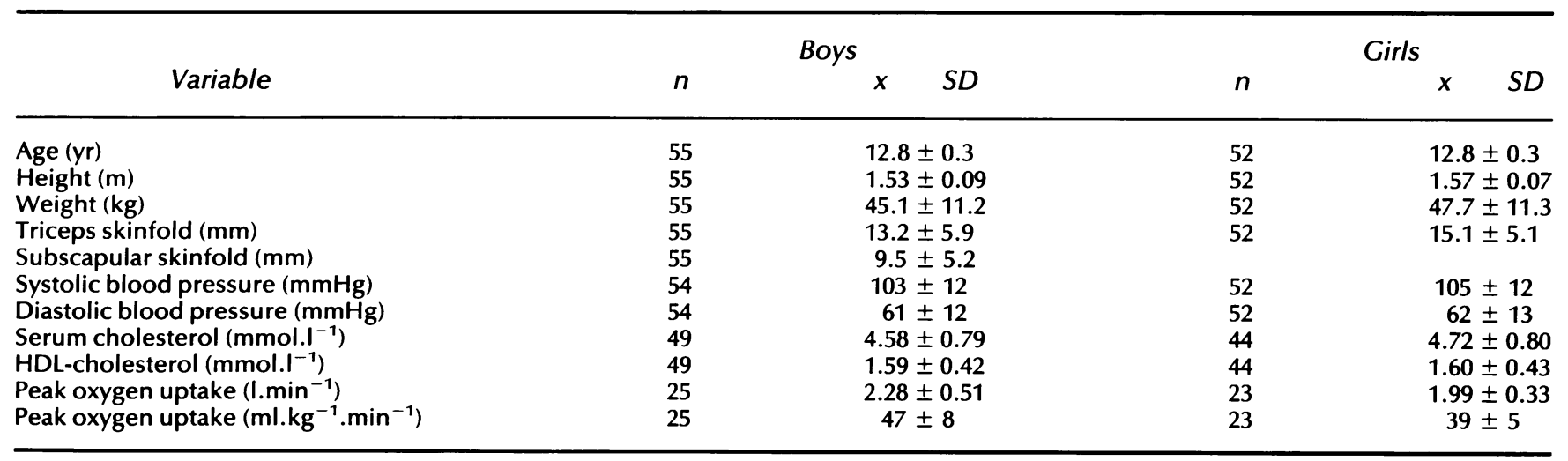


considerably lower than the mean level observed in the present study. Wynder's 'cut-off point for coronary risk' was set at $4.65 \mathrm{mmol}^{-1} \mathrm{l}^{-1}$, and 41 (38 per cent) of our children exceeded this level.

The problems associated with comparing serum cholesterol levels between studies are, however, well documented $^{25}$. So although it is inherently interesting to make between-study comparisons, the emphasis should be placed upon the within-study analysis of sex, age and sexual maturity differences in lipid and lipoprotein profile with large numbers of children. This is the direction our future work will take.

Subsequent discussion with the children indicated that many would be willing to undergo a 12 hour fast prior to blood sampling. This would enable an estimation of serum triglyceride and LDL-cholesterol to be obtained and will therefore be addressed in future work.

\section{Cigarette smoking}

Analysis of the relevant questions in the questionnaire revealed that three girls and two boys smoked cigarettes. This finding is in accord with observations from a much larger study carried out by one of us and reported elsewhere ${ }^{26}$.

\section{Cardiorespiratory fitness (peak $\mathrm{VO}_{2}$ )}

The peak $\hat{\mathrm{VO}}_{2}$ of the boys was significantly higher than that of the girls whether expressed in $1 . \mathrm{min}^{-1}(\mathrm{p}$ $<0.05)$ or in relation to body weight $(p<0.01)$. There appears to be no other comparable published report of untrained British children of this age exercised to exhaustion on the treadmill. The results are well within the range of values reported from elsewhere in the world ${ }^{27}$.

No significant relationship ( $p>0.05$ ) was identified between weight-related peak $\mathrm{VO}_{2}$ and either serum cholesterol, HDL-cholesterol or blood pressure in either girls or boys. Weight-related peak $\mathrm{VO}_{2}$ in boys was negatively correlated with both triceps skinfold thickness $(r=-0.70, p<0.01)$ and subscapular skinfold thickness $(\mathrm{r}=-0.74,0<0.01)$, indicating the lower level of cardiorespiratory fitness in relation to body weight of the more obese boys. No significant relationship ( $p>0.05$ ) between weight-related peak $\mathrm{VO}_{2}$ and triceps skinfold thickness was detected in girls. Due to the small number of subjects involved, these analyses must be interpreted cautiously.

Some investigators have reported that subjects with high values of weight-related peak $\mathrm{VO}_{2}$ to have lower levels of serum cholesterol ${ }^{28}$. Others, sometimes from the same laboratory, have reported no significant relationship between weight-related peak $\mathrm{VO}_{2}$ and serum cholesterol ${ }^{29}$.

Atomi and his associates ${ }^{30}$ found a significant positive correlation between weight-related peak $\mathrm{VO}_{2}$ and HDL-C in 10 to 12 year old boys, but not in similarly aged girls. Verschuur and his colleagues ${ }^{31}$ reported conflicting results. They studied 215 girls and 195 boys, aged 13 to 14 years, and found a significant positive relationship between weightrelated peak $\mathrm{VO}_{2}$ and $\mathrm{HDL}-\mathrm{C}$ in the girls only.
Wilmore reported no significant relationship between weight-related peak $\mathrm{VO}_{2}$ and either diastolic or systolic blood pressure in his study of 308 boys aged between 13 and 15 years $^{28}$. But in an earlier investigation of 958 to 12 year old boys, the same researcher had reported a significant negative correlation between weight-related peak $\mathrm{VO}_{2}$ and systolic blood pressure ${ }^{29}$.

The research results available are equivocal and often difficult to interpret because of the interrelationship of peak $\mathrm{VO}_{2}$, blood lipids, body fatness, blood pressure and sexual maturity. Further study is required.

\section{Physical activity}

Continuous heart rate data over 12 hours were obtained on 32 boys and 44 girls (i.e. 71 per cent of the sample). This is a considerably higher success rate than the 50-55 per cent achieved by Kemper ${ }^{32}$ using a heart rate integrator. The results revealed that the girls maintained their heart rates above 159 beats. $\min ^{-1}$ for $1.5 \pm 1.7$ (mean \pm standard deviation) per cent of the time. The boys managed 2.6 \pm 3.2 per cent of the time at this intensity, but the difference between the sexes was not significant ( $p$ $>0.05$ ). Eleven boys ( 34 per cent) and 15 girls ( 34 per

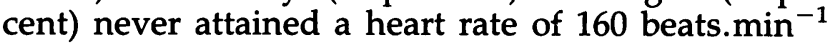
during the period surveyed.

These findings are in accord with those of Seliger et al. ${ }^{33}$ who monitored a group of 12 boys of similar age and reported that heart rates of over $150{\text { beats. } \text { min }^{-1}}^{-1}$ were rare and only fleetingly encountered. Gilliam et al. ${ }^{34}$ monitored a group of seven year old children over a 12 hour period and reported that the boys spent 2.9 per cent of their time and the girls 1.3 per cent of their time with heart rates $>160$ beats. min $^{-1}$.

These findings are very similar to our own, but the interpretation of continuous heart rate data is complex. It not only reflects the metabolism of the child, but also the transient emotional state, the prevailing climatic conditions, and the specific muscle groups which perform the activity ${ }^{35}$. The primary consideration, in this context, should be the number and length of sustained periods above threshold heart rates. The period of monitoring should be extended to at least three days. Our current research encompasses this, and we have reported the results of three day monitoring of both secondary and primary schoolchildren in this manner elsewhere ${ }^{36}$.

\section{Conclusions}

The willingness and enthusiasm of the children, parents and schools to take part in the project have clearly demonstrated the feasibility of a large scale study being successfully pursued in the United Kingdom.

The estimation of relative physical activity through continuous heart rate monitoring has been shown to be feasible. The laboratory determination of peak $\mathrm{VO}_{2}$ has confirmed the willingness of untrained children, if encouraged, to run to exhaustion on the treadmill. None of the children or their parents withheld consent to blood sampling, and sufficient 
blood for analysis was obtained from 87 per cent of the subjects. Many of the children expressed a willingness to fast for 12 hours prior to blood sampling. No problems emerged from the analysis of sexual maturity.

An exhaustive analysis of the results of this preliminary work was not attempted as subsequent work will involve the same variables being examined with more subjects and enhanced techniques. However, the results indicate that British children have relatively high serum cholesterol levels, and that many exhibit low levels of physical activity. Fourteen per cent of the children examined were classified as 'overweight'.

In conclusion, we have demonstrated the feasibility of carrying out a large scale study of coronary risk factor variables in British children, and identified the need to explore the relationship between cardiorespiratory fitness, physical activity and coronary risk factor variables with reference to chronological age, sex and sexual maturity.

\section{Acknowledgements}

The technical assistance of Chris Harwood, Joanne Williams, Clive Williams and Alison Husband is gratefully acknowledged. The work was supported by the Northcott Devon Medical Foundation and the Oxenham Will Trust.

\section{References}

1 Saltykov, S. Jugenoliche und beginnende atheroscklerse, Korrespondenzblatt fur Schweizer Aertz Basel, XLV: 1057 In R.D. Voller and W.B. Strong, Pediatric aspects of atherosclerosis American Heart Journal 1981, 101, 815-836

2 McGill, H.C. Persistent problems in the pathogenesis of atherosclerosis Atherosclerosis 1984, 4, 443-451

3 Keys, A., Aravanis, C., Blackburn, H., van Bachem, F.S.P., Buzina, R., Djordjevic, B.S., Dontas, A.S., Fidanza, F., Karvonen, M.J., Kimara, N., Lekos, D., Monti, M., Puddu, V. and Taylor, H.L. Epidemiological studies related to coronary heart disease: Characteristics of men aged 40-59 in seven countries Acta Medica Scandinavica 1966, 460, 1-392

4 Armstrong, N. and Davies, B. The prevalence of coronary risk factors in children Acta Paediatrica Belgica 1980, 33, 209-217

5 Berenson, G.S. 'Causation of Cardiovascular Risk Factors in Childhood' Raven Press, New York, 1986

6 Newman, W.P., Freedman, D.S., Voors, A.W., Gard, P.D., Srinivasan, S.R., Cresanta, J.L., Williamson, G.D., Webber, L.S. and Berenson, G.S. Relation of serum lipoprotein levels and systolic blood pressure to early atherosclerosis New England Journal of Medicine 1986, 314, 138-144

7 Glueck, C.J. Pediatric primary prevention of atherosclerosis New Eñgland Journal of Medicine 1986, 314, 175-177

8 Armstrong, N., Balding, J., Gentle, P. and Kirby, B. Coronary prevention in children: Setting up the project Perspectives 1987, 31, 101-09 (ISBN 85068090 5)

9 Tanner, J.M. 'Growth at Adolescence' 2nd ed Blackwell Scientific Publications, Oxford, 1962

10 Royal College of Physicians. Obesity Journal of the Royal College of Physicians 1983, 17, 3-58
11 Berenson, G.S. 'Cardiovascular Risk Factors in Children' Oxford University Press, New York, 1980

12 Lopes-Virella, M.F., Stone, P., Ellis, S. and Colwell, J.A. Cholesterol determination in high density lipoproteins separated by three different methods Clinical Chemistry 1977, 23, 882-884

13 Siedel, J., Schlumberger, H., Klose, S., Ziegenhorn, J. and Wahlefeld, A.W. Improved reagent for the enzymatic determination of serum cholesterol Journal of Clinical Chemistry and Clinical Biochemistry 1981, 19, 838-839

14 Tell, G.S., Tuomilheto, J., Epstein, F.H. and Strasser, T. Studies of atherosclerosis determinants and precursors during childhood and adolescence World Health Organisation Bulletin 1986, 64, 595-605

15 European Atherosclerosis Society. Strategies for the prevention of coronary heart disease: A policy statement of the European Atherosclerosis Society European Heart Journal 1987, 8, 77-78

16 Friedewald, W.T., Levy, R.I. and Fredrickson, D.S. Estimation of the concentration of low-density lipoprotein cholesterol in plasma, without use of the preparative ultracentrifuge Clinical Chemistry 1972, 18, 499-502

17 Cooper, D.M., Weiler-Ravell, D., Whipp, B.J. and Waserman, K. Aerobic parameters of exercise as a function of body size during growth in children Journal of Applied Physiology 1984, 56, 628-634

18 Karvonen, M.J., Cwalbinska-Moneto, J. and Synajakangas, S. Comparison of heart rates measured by ECG and microcomputer Physician and Sports Medicine 1984, 12, 65-69

19 Tsanakas, J.N., Bannister, O.M., Boon, A.W. and Milner, R.D.G. The Sport Tester, a device for monitoring the free running test Archives of Disease in Childhood 1986, 61, 912-914

20 Leger, L. and Thivierge, M. Heart rate monitors: Validity, stability, and functionality Physician and Sports Medicine 1988, 16, 143-151

21 Sady, S.P. Cardiorespiratory exercise training in children Clinics in Sports Medicine 1986, 5, 493-514

22 Wynder, E.L., Williams, C.L., Laakso, K. and Levenstein, M. Screening for risk factors for chronic disease in children from fifteen countries Preventive Medicine 1981, 10, 121-132

23 Orchard, T.J., Rodgers, M., Hedley, A.J., Mitchell, J.R.A. Changes in blood lipids and blood pressure during adolescence British Medical Journal 1980, 280, 1563-1567

24 World Health Organisation, Expert Committee 'Prevention of Coronary Heart Disease' 1982, WHO, Geneva

25 Blank, D.W., Hoeg, J.M., Kroll, M.H. and Ruddel, M.E. The method of determination must be considered in interpreting blood cholesterol levels Journal of the American Medical Association 1986, 25, 2867-2870

26 Balding, J. 'Young People in 1987' HEA Schools Health Education Unit, Exeter 1988

27 Krahenbuhl, G.S., Skinner, J.S. and Kohrt, W.M. Developmental aspects of maximal aerobic power in children Exercise and Sports Science Reviews 1985, 13, 503-538

28 Wilmore, J.H., Constable, M.S., Stanforth, M.S., Tsao, M.S., Rotkis, T.C., Paicius, R.M., Mattern, C.M. and Ewy, G.A. Prevalence of coronary heart disease risk factors in 13 to 15 year old boys Journal of Cardiac Rehabilitation 1982, 2, 223-233

29 Wilmore, J.H. and McNamara, J.J. Prevalence of coronary heart disease risk factors in boys, 8 to 12 years of age Journal of Pediatrics 1974, 84, 527-533

30 Atomi, Y., Kuroda, Y., Asami, T. and Kawahara, T. 
$\mathrm{HDL}_{2}$-cholesterol in children (10 to 12 years of age) related to $\mathrm{VO}_{2}$ max, body fat and sex. In J. Rutenfranz, R: Mocellin and F. Klimt (eds) 'Children and Exercise XII' Human Kinetics, Champaign, Illinois, 1986, pp 167-172

31 Verschuur, R., Kemper, H.C.G. and Besseling, C.W.M. Habitual physical activity and health in 13 and 14 year old teenagers. In J. Ilmarinen and I. Valimaki (eds) 'Children and Sport' Springer-Verlag, New York, 1984, pp 255-261

32 Kemper, H.C.G. 'Growth, Health and Fitness of Teenagers' Karger, Basel, 1985

33 Seliger, V.S., Trefny, S., Bartunkova, S. and Pauer, $M$. The habitual activity and physical fitness of 12 year old boys Acta Paediatrica Belgica 1974, 28, 54-59

34 Gilliam, T.B., Freedson, P.S., Geenen, D.L. and
Shahraray, B. Physical activity patterns determined by heart rate monitoring in 6-7 year old children Medicine and Science in Sports and Exercise 1981, 13, 65-67

35 Armstrong, N. Children's physical activity patterns and coronary heart disease. In Coronary Prevention Group (1989), 'Should the Prevention of Coronary Heart Disease Begin in Childhood?' Coronary Prevention Group, London, 1989, pp 37-44

36 Armstrong, N., Balding, J., Bray, S., Gentle, P. and Kirby, B. The physical activity patterns of 10 and 13 year old children. In G. Beunen, J. Ghesquiere, R. Reybrouck and A. L. Claessens (eds) 'Children and Exercise XIV' Schriftenreihe der HamburgMunnheimer-Stiftung fur Informationsmedizin, Hamburg (in press) 1990 